\title{
PRAZER E SOFRIMENTO NO TRABALHO: UM ESTUDO DIAGNÓSTICO JUNTO AOS TRABALHADORES QUE PRATICAM PÁRA-QUEDISMO EM SEUS MOMENTOS DE LAZER
}

\author{
Ednaldo Antonio da Silva ${ }^{1}$ \\ Marcos Antonio Rodrigues de Arruda Filho ${ }^{2}$ \\ Shirley Macedo Vieira de Melo ${ }^{3}$
}

Resumo: A presente pesquisa teve como objetivo verificar se os trabalhadores de empresa diversas, do sexo masculino, no exercício da função há mais de um ano, tiveram sentimentos de prazer e sofrimento gerados no trabalho no dia a dia, e se adotavam estratégias como o pára-quedismo para lidar com esses sentimentos. Foram entrevistados seis funcionários. As entrevistas foram não-diretivas, e fez-se uma pergunta disparadora para estimular os depoimentos. Por meio de uma metodologia qualitativa, analisaram-se os depoimentos fenomenologicamente, partindo-se da divisão do texto em unidades de significado, possibilitando a construção de uma compreensão psicológica acerca das vivências. Para cada depoimento foi elaborada uma síntese específica dos elementos do vivido. Os resultados mostraram que os trabalhadores experimentam mais prazer do que sofrimento no contexto de trabalho.

Palavras-chave: pára-quedismo, trabalho, prazer, sofrimento, psicologia do trabalho

Pleasure and suffering at work: A diagnosis study about workers that practice sky-diving in leisure time (Abstract): The present research had the objective to verify whether male workers in different companies, enrolled in their jobs for more than a year, had pleasant and suffering feelings in their daily lives, and if they adopted strategies such as sky-diving to cope with these feelings. Six employees were interviewed. The interviews were no-directive, and a stimulating question was presented in order to trigger participants' statements. Using a qualitative methodology, statements were phenomenologically analysed, by dividing

\footnotetext{
${ }^{1}$ Faculdade Integrada do Recife, Pernambuco, Brasil, E-mail: nicoitaenga@yahoo.com.br http://buscatextual.cnpq.br/buscatextual/visualizacv.jsp?id=K4254017A8

2 Faculdade Integrada do Recife, Pernambuco, Brasil, E-mail: nicoitaenga@yahoo.com.br http://buscatextual.cnpq.br/buscatextual/visualizacv.jsp?id=K4254017A8

${ }^{3}$ Faculdade Integrada do Recife, Pernambuco, Brasil 
the text into units of meaning, and thus allowing the construction of a psychological understanding of participants' experiences. For each statement a specific synthesis of experienced elements was elaborated. Results showed that those workers experienced more pleasure than suffering in the work context.

Keywords: sky-diving, work, pleasure, suffering, psychology of work

\section{Introdução}

A palavra trabalho tem diversos significados, desde dor, tortura e suor no rosto, até a transformação de elementos da natureza em objetos de cultura. Para sobreviver o homem precisa realizar-se e trabalhar (Macêdo, 2006).

A autora afirma ainda que o trabalho pode significar realização de uma obra, através da qual o sujeito se expressa e é reconhecido pelos demais atores da sociedade, permanecendo para além da sua própria vida. Por outro lado, o trabalho também pode ser fonte de sofrimento, esforço rotineiro, liberdade podada. Neste aspecto, o trabalhador precisa ter disponibilidade de tempo para executar o seu trabalho. E esta disponibilidade requer renunciar a liberdade, ou seja, podar alguns aspectos da liberdade em troca do trabalho. Muitos sujeitos trocam o lazer pela segurança que o trabalho gera. Esta troca também proporciona status ao sujeito perante a sociedade.

$\mathrm{O}$ ingresso no mundo do trabalho pelo indivíduo na vida adulta lhe confere aquisição de qualificações que são esperadas pelo espaço de trabalho adquirido, sendo estas incorporadas à identidade do sujeito. Tal afirmação implica a conclusão de que o desemprego e a inatividade revelam uma dimensão subjetiva e uma repercussão social que vão além dos dados estatísticos e dos parâmetros econômicos. Com isso, a inserção no mundo concreto do trabalho aparece como seqüência lógica de uma vida normal e como atributo de valor em uma sociedade caracterizada pelo fator produtivo.

Originada do latim tripallium, instrumento de tortura, a palavra trabalho lembra fardo, sofrimento e dor. No entanto, o trabalho é o símbolo da liberdade humana, através do qual o homem se diferencia do animal e tem a habilidade de transformar a natureza para satisfazer suas necessidades (Macêdo, 2006).

Para Codo, Sampaio e Hitomi (1992) o trabalho é a expressão máxima da subjetividade humana. E segundo Macêdo (2006) tem-se, assim, a preocupação em entender como o homem se constrói subjetiva e socialmente através do trabalho, tornando-se um dos focos de estudo da psicologia do trabalho, que está eticamente comprometida com a contextualização social e histórica do homem, para produzir conhecimentos sobre novos modos de 
fazer em relação à saúde psicológica dos indivíduos, constituindo que estes são seres singulares e coletivos, inseridos num contexto de relação sociais.

Assim Pagès (1993) apud Codo (1998) refere que a falta de condições financeiras para atividades de lazer e tempo disponível para sair da rotina de trabalho, somado com a organização dos processos de trabalho nos quais estão inseridos os trabalhadores, produz graves conseqüências sobre a sua saúde, originando principalmente a separação entre concepção e execução, introduzidas pelos modelos de gestão taylorista e fordista.

Dejours (1992) afirma que executar uma tarefa sem envolvimento material ou afetivo exige esforço de vontade que, em outras circunstâncias, é suportado pelo jogo da motivação e do desejo. A vivência depressiva em relação ao trabalho e a si mesmo alimenta-se da sensação de adormecimento intelectual, de esclerose mental, de paralisia da fantasia e da imaginação; na verdade, marca de alguma forma o triunfo do condicionamento em relação ao comportamento produtivo e criativo. Para esse pensador, no que diz respeito à relação do homem com o conteúdo significativo do trabalho, é possível considerar, esquematicamente, dois componentes: o conteúdo significativo em relação ao sujeito e o conteúdo significativo em relação ao objeto. Quando o progresso e o avanço dessa relação são bloqueados por algum motivo ou circunstância, observa-se a incidência do sofrimento.

O autor ainda refere que o sofrimento, por seu turno, é desdobrado: o ponto de incidência proveniente das ações mecânicas, conteúdo ergonômico da tarefa, é o corpo e não o aparelho mental; esse último será afetado pela insatisfação propiciada pelo conteúdo significativo da tarefa a ser executada, transformando em sofrimento bem particular, cujo alvo, antes de tudo, é a subjetividade, ou seja, a mente.

E assim, no âmbito de escapar do estresse e da aceleração causada pela modernidade, está crescendo o número de adeptos às novas práticas alternativas e aos esportes individuais ou "não dependentes do coletivo". Essas atividades caracterizam-se pela individualização, retratada na sociedade contemporânea. O modernismo e seus princípios de produção, coletivismo, consumo e sacrifício, está sendo deixado para trás em busca do prazer e da liberdade individualizada (Piucco, 2005).

Deste modo, o esporte radical leva o indivíduo a esquecer seu sofrimento. $\mathrm{O}$ trabalhador precisa ser escutado e esta escuta desvia a energia psíquica causada pelas demandas do trabalho para outras atividades que venham trazer o prazer. É pela forma da linguagem que o trabalhador se comunica. Berger \& Luckmann (1985) argumentam que é com a linguagem que o homem passa a poder operar mentalmente com objetos ausentes de seu campo perceptivo e vivencial imediato. Através da linguagem, homens e mulheres emanciparam-se da imediatez da realidade prática e passaram a 
usufruir de uma capacidade exclusiva de sua espécie: a de planejar, regular e refletir sobre a própria atividade.

Para Anderson (1985) o trabalhador está tentando verbalizar seu sofrimento. É por meio da linguagem que o trabalhador cria e sintetiza a concepção de mundo, sendo ela, ao mesmo tempo, produto social e histórico. Constitui-se como elemento e um produto da atividade prática do homem, e em seu aspecto semântico continua sendo determinada por fatores sociais, embora goze de relativa autonomia enquanto sistema lingüístico (Bakhtin, 1981).

E retomando Berger (1985), compreende-se que é através do discurso que o trabalhador aprende a ver o mundo e o reproduz em sua fala. Se o discurso é determinado, ao menos em parte, por formações ideológicas, se a consciência é constituída a partir dos discursos assimilados, e se não há pessoas constituídas fora de seus contextos de relações sociais, pode-se dizer que não há individualidade absoluta nem no nível do sujeito, nem no nível do discurso.

O trabalhador, segundo Souza Filho (1983), quando fala está colocando para fora todos os seus sintomas e é pela palavra que haverá o desdobramento de significados. O inconsciente se manifesta muitas vezes de maneira involuntária (o relato do ato falhado); o sintoma é plástico e se molda. Através de um relato de uma pessoa onde aparece o erro ou engano, pode ser de fato o verdadeiro sentido da pessoa, no caso de formação inconsciente. Muitas vezes o inconsciente articula no outro do desejo pessoal.

Assim, Dejours (1994) aponta que, para poder deixar para trás o sofrimento, é preciso interpretar determinadas manifestações do sofrimento no trabalho como pecado, loucura, preguiça, malandragem ou patologia que depende daquele que o diagnostica, de sua inserção em determinados discursos, da utilização que faz do vocabulário disponível em sua época, da origem social do trabalhador diagnosticado e do seu capital social.

O grande mérito de Dejours (1994), ao considerar a significação e o sentido do sofrimento como dimensões essenciais no entendimento da relação saúde-trabalho, foi colocar-se à escuta do trabalhador para compreender o que lhe ocorria. Assim, a fala do trabalhador passou a configurar um privilegiado instrumento de pesquisa e de intervenção (Uchida,1996, apud Codo, 1998). Ao dar voz aos trabalhadores, constatou-se que, entre eles, a doença é geralmente associada à preguiça, vagabundagem ou malandragem. Diante da adversidade, esses trabalhadores tentam dominar a doença de alguma maneira. Partindo desse princípio, Dejours (1992) elaborou o conceito de "ideologia defensiva", como construção social que possibilita dominar e tentar fazer desaparecer da consciência o sofrimento.

Segundo a teoria dejouriana, o adoecimento pode acontecer devido a uma "retenção da energia pulsional" por uma situação de trabalho que impede a descarga adequada da carga psíquica. É notória a tentativa psicodinâmi- 
ca de reafirmar a centralidade do sofrimento no processo saúde-doença-cuidado. No entanto, essa perspectiva teórica esbarra em pontos críticos. Repete o modelo de explicação causal, ao dicotomizar o sofrimento em criativo e patogênico, e reproduz aspectos que tentava superar em relação à psicopatologia.

Nesse sentido, é possível perceber que a psicodinâmica ainda mantém-se, um tanto quanto, presa aos modelos termodinâmico e biológico, herdados da psicanálise freudiana e da ergonomia. Fato que fica evidente quando Dejours (1992) desenvolve a abordagem econômica do funcionamento psíquico, a partir do modelo médico. Sob essa ótica, a manifestação do sofrimento é interpretada como resultado de um enfraquecimento das estratégias coletivas dos trabalhadores e não como uma conseqüência de situações relacionadas ao trabalho.

A partir da psicanálise como instrumento de crítica para a organização do trabalho, Dejours, (1992) pergunta: "há lugar para os trabalhadores serem sujeitos dos seus desejos?" Não se pode esquecer que o desejo, desde Hegel e, posteriormente em Lacan, é sempre desejo do Outro. Mesmo empreendendo consideráveis esforços para fazer avançar o conhecimento da relação saúde-trabalho, a psicodinâmica dejouriana ainda encontra algumas dificuldades, principalmente quando utiliza, de forma vaga e imprecisa, conceitos como "equilíbrio psíquico", "energia psíquica" e "normalidade", para explicar o sofrimento. Assim, ao polarizá-lo em patogênico e criativo, Dejours (1994), reproduz uma longa tradição que, do nascimento da clínica à psicodinâmica do trabalho, transforma o sofrimento em adoecimento, fornecendo elementos teóricos que colaboram na construção da identidade do trabalhador doente.

Informa Gomes (2004) que, com isso, os trabalhadores constroem novas formas de lidar com estes problemas, utilizando atividades de lazer ou esportes radicais para superar o sofrimento no trabalho.

Marcellino (1996) diz que, no sentido do preenchimento da inquietação humana em busca da melhoria da qualidade existencial, especialmente na prática esportiva relacionada à manutenção de uma boa saúde, ou mesmo o alívio do stress diário depois de algumas horas de trabalho, o universo tem-se ampliado em direção a novos segmentos de práticas, como por exemplo: As atividades físicas de aventura na natureza, que colocam o indivíduo em contato com a possibilidade da morte iminente. Os esportes de aventura oferecem a possibilidade de vivenciar sentimentos de prazer, em função de características que promovem, inclusive, a ampliação do sentido de limite da liberdade e da própria vida.

Segundo Tahara (2002) "Os esportes radicais reconstroem a identidade do trabalhador que está fragmentada. Neste caso, o processo de adoeci- 
mento conduz como resultado final, à configuração da identidade de trabalhador-doente".

Segundo Dejours (1992), no espaço da fábrica, a construção dessa identidade implica em submissão ao discurso médico e sair dessa condição não depende apenas da vontade individual. É preciso a intervenção no âmbito institucional. O próprio discurso da medicina ocupacional produz uma cultura que fornece subsídios para a formação da identidade do doente entendida como processo pelo qual o indivíduo se reconhece e constrói a significação da sua vida com base no atributo cultural de ser doente - a ponto de excluir outras referências culturais.

Conforme aponta o mesmo autor, outros mediadores sócio-funcionais contribuem para a constituição dessa identidade, como um conjunto de práticas instituídas, que nas empresas assumem formas de: exames admissionais, periódicos e demissionais; avaliação de desempenho; programas de qualidade de vida, de dependência química e de anti-stres; outros preferem sair do ambiente fabril para explorar e descarregar suas energias na natureza, na expressão de liberdade que o pára-quedismo proporciona ao trabalhador que precisa extravasar suas tensões.

$\mathrm{O}$ autor ainda refere que esse processo, entretanto, não acontece sem resistências dos atores sociais envolvidos. A insubordinação ao imperativo organizacional da transformação do sofrimento em adoecimento leva à instituição de uma grande diversidade de movimentos. Criam-se diversas alternativas de sobrevivência emocional e material no espaço da fábrica, uma verdadeira cultura do contra-afastamento por motivos médicos. A socialização dessas ações entre alguns trabalhadores deixa entrever uma organização política mínima e um nível cultural desorganizado.

Moraes (1990) refere que as Atividades Físicas de Aventura na Natureza (AFAN) são entendidas como aquelas atividades físicas de tempo livre que buscam uma aventura imaginária sentindo emoções e sensações hedonistas fundamentalmente individuais, em interação com um ambiente ecológico ou natural. São atividades que se situam no seguimento dos novos valores sociais da pós-modernidade.

Piucco (2005) afirma que, nesse pressuposto, os sujeitos envolvidos nas vivências junto à natureza, têm efetivas oportunidades de auto-desafio e de rompimento com a monotonia do dia-a-dia. O risco controlado pelo auxílio de dispositivos utilizados nas práticas de atividade física de aventura proporciona sensações, emoções e percepções bastante diversas daquelas do cotidiano, associadas aos sabores da aventura, do ineditismo, da novidade, que são características nessas práticas de lazer. Podem, também, nessas experiências, "brincar" e "transgredir" os limites que lhes são impostos pela própria sociedade, os quais se traduzem na vasta gama de códigos, normas e símbolos presentes na estruturação da vida em coletividade. 


\section{Procedimentos Metodológicos}

O caminho metodológico escolhido para investigar as experiências de trabalhadores de empresas privadas com funções diversas, praticantes de esporte radical pára-quedismo foi a análise fenomenológica dos relatos das vivências, fornecidos pelos próprios trabalhadores. Especificamente, nos detivemos naqueles funcionários empregados há mais de um ano e praticantes de pára-quedismo há mais de seis meses.

$\mathrm{O}$ termo fenomenologia psicológica refere-se à fenomenologia como um método aplicado aos problemas de natureza psicológica, ou utilizado a um nível psicológico de questionamento. Consiste num processo específico para abordar a consciência e a experiência humana imediata. Pode ser definido como um tipo de observação sistemática e de descrição da experiência de um indivíduo consciente, numa dada situação (Cury, 1987).

\section{Contextos da Pesquisa}

A empresa já está no mercado há mais de 10 anos e é filiada à Federação Pernambucana e à Confederação Brasileira de Pára-quedismo. O pára-quedismo é um esporte que exige alto nível de conhecimento e especialização e estes são os pontos fortes da equipe Gravidade Pára-quedismo.

Todos os seus instrutores são homologados e certificados por estas instituições e trabalham com equipamentos de última geração, sempre visando a segurança dos seus alunos.

O curso GRAVIDADE PÁRA-QUEDISMO ADVANCED SKYDIVING PROGRAM tem como objetivo fazer evoluir o desempenho individual do atleta, melhorando a sua condição técnica, aumentando o poder de decisão e avaliação, aguçando a capacidade de agir em todas as searas do pára-quedismo: segurança, treinamento em solo, concentração, queda-livre, navegação e pouso.

Todo o curso é ONE-ONE composto por sete módulos, sendo eles subdivididos em: Módulo 1 - Teoria: separação (TRACK), saída da aeronave, segurança e comando; Módulo 2 - Mantis position; Módulo 3 - Movimento à frente / trás; Módulo 4 - Nível; Módulo 5 - Curvas no eixo; Módulo 6 - Movimentos laterais (Side slides); Módulo 7 - Trabalho Relativo - Two-way.

O primeiro módulo é apenas teórico, sendo o restante representado por pelo menos um salto, de acordo com a evolução individual e aproveitamento do aluno. Em todos os saltos o aluno é avaliado de acordo com o aprendido no módulo 1, bem como, atitudes de segurança, capacidade de decisão dentro das situações propostas pelo instrutor, navegação e pouso. São necessários os seguintes pré-requisitos: Progressão ASL / AFF completa; Aeronave: sair estável, de mergulho ou de frente para o vento relativo; Controle do 
velame: navegação e pouso dentro do aeroclube, de vento de nariz. Tipos de vento. E estratégia para progressão.

Cada módulo possui sua teoria individual. O aluno recebe o material didático de acordo com a progressão. Todos os saltos são treinados em solo, com teoria e prática de acordo com o aprendizado e nível de dificuldade de cada módulo. Antes de cada salto é feito um briefing e após cada salto é realizado o debriefing. Todos os saltos são filmados e as imagens utilizadas no debriefing. No fim do curso o aluno recebe um DVD com todas as imagens. Os alunos reprovam nos módulos caso os objetivos não tenham sido atingidos. Em caso de reprovação, o aluno faz novamente o salto pertinente. No final do curso o aluno recebe um certificado de conclusão com a anuência do clube Gravidade Pára-quedismo e da diretoria técnica da Federação Pernambucana de Pára-quedismo.

Para fazer as entrevistas, um dos investigadores fez o curso básico de pára-quedismo. ${ }^{4} \mathrm{O}$ objetivo deste curso foi identificar as tarefas exercidas pelos pára-quedistas, o grau de responsabilidade exigido por elas, e ainda como os trabalhadores praticantes deste esporte lidam com momentos de prazer e de sofrimento. Pretendia-se também compreender qual a relação destas tarefas no curso com seu ambiente de trabalho, de modo a compreender e ter embasamento para interpretar os dados fornecidos para uma melhor análise.

\section{Participantes}

Esta pesquisa contou com a participação de seis trabalhadores (pára-quedistas), do sexo masculino, com idades entre 29 e 55 anos $^{5}$, empregados há mais de um ano e praticantes do esporte de Pára-Quedismo há mais de seis meses. As entrevistas foram realizadas em aeroclube ${ }^{6}$ disponibilizado no próprio ambiente das aterrissagens. Este número resultou da aplicação do critério de saturação. Foram gravados em mp3 os depoimentos daqueles trabalhadores que se dispuseram e consentiram em participar da pesquisa, após terem sido suficientemente informados sobre os objetivos da mesma.

Optou-se por uma modalidade de entrevista não-diretiva. A entrevista não-diretiva, como técnica qualitativa de coleta de dados, é o inverso do questionário que se baseia em perguntas. A entrevista é aqui "aberta" e "centrada", quer dizer, ela se baseia, não nas reações do entrevistado a perguntas precisas, mas na expressão livre de suas idéias sobre um assunto. Para um

\footnotetext{
${ }^{4}$ Esta fase inicial de observação foi realizada de 7/04 a 11/04 de 2008, na Escola de PáraQuedismo, Gravidade.

${ }^{5}$ Sendo um de 29 , outro de 35 , outro de 44 , outro de 46 e dois de 55 anos de idade.

6 Aeroclube de João Pessoa/PB, durante os intervalos de seus saltos, no dia 11 de Abril de 2008 com início às 14:00 horas.
} 
entrevistador, ser "não diretivo" é querer não impor nada ao entrevistado, mas obter dele expressões espontâneas, absolutamente não devidas a induções vindas da situação do encontro, ou de suas próprias atitudes, comportamentos e reações no momento deste encontro (Mucchielli, 1991).

Nesta pesquisa foi feita uma pergunta disparadora, a partir da qual o participante foi estimulado a discorrer livremente sobre um tema que constitui o foco de pesquisa, sendo feitas pequenas intervenções visando esclarecimentos necessários. A questão disparadora foi a seguinte:

"Estamos pesquisando sobre prazer e sofrimento no trabalho. Como a Prática do Pára-Quedismo influencia significativamente, aliviando seu estresse do dia-a-dia do trabalho?".

\section{Procedimentos}

Os pesquisadores entraram em contato com os trabalhadores praticantes de pára-quedismo e consultaram-nos sobre o interesse em participar da pesquisa, explicando-lhes os objetivos da mesma. Os colaboradores que concordaram em participar da pesquisa tiveram suas dúvidas esclarecidas e foram devidamente informados de que a sua participação seria voluntária, sob a forma de depoimentos gravados, sendo omitidos dados pessoais que pudessem levar à identificação dos participantes. Para os que manifestaram interesse, foi agendado um segundo encontro, no qual houve a leitura e assinatura do Termo de Consentimento Livre e Esclarecido e ocorreram as entrevistas propriamente ditas, as quais foram gravadas, com o consentimento de cada participante, e transcritas posteriormente. Na seqüência deste procedimento, os pesquisadores solicitaram outro encontro para que cada participante lesse o texto referente à transcrição do seu depoimento, para eventuais correções ou esclarecimentos que julgasse necessários. As entrevistas foram realizadas nas dependências do próprio Aeroclube, na sala destinada à orientação dos saltos.

\section{Análises dos Depoimentos}

A partir da proposta de Amatuzzi (2001), a análise dos depoimentos deste estudo foi efetivada por meio dos seguintes passos:

1. Os depoimentos gravados foram transcritos, tendo sido efetivada uma literalização, de forma a obter uma adequação gramatical. O texto do primeiro depoimento foi dividido em unidades de significado.

2. Elaborou-se a compreensão psicológica destas unidades de significado e a construção da síntese específica deste depoimento.

3. A seguir elaborou-se a compreensão psicológica de cada depoimento e a síntese específica do mesmo, comparando-a à síntese específica do depoimento anterior; procedeu-se desta forma, sucessivamente, até 
alcançar-se o ponto de saturação, ou seja, a partir do qual os pesquisadores não encontraram nenhum elemento novo, inédito, em relação à análise dos depoimentos anteriores.

4. Finalmente, efetivou-se uma Síntese Geral, construída como uma apreensão dos elementos do vivido considerados como elementos invariantes presentes no conjunto de todos os depoimentos.

\section{Resultados/Discussão}

Alguns aspectos foram percebidos nos discursos dos trabalhadores que praticam este esporte e serão apresentados a seguir:

É possível perceber que, no geral, há um bom relacionamento entre os trabalhadores praticantes desse esporte - um entrevistado disse que um pára-quedista reconhece o outro como um amigo e companheiro de aventura.

Conforme o discurso de: J.J.S., 35 anos, casado, advogado há seis anos e praticante de pára-quedismo há dois anos: "Eu vejo no pára-quedista o meu grande amigo, que vai experimentar o que eu experimentei. O outro é para mim alguém com quem tenho que conviver a vida toda. Pode ser que em situação adversa o companheiro de salto possa me socorrer no momento que eu necessitar. O importante é que temos os mesmos sentimentos: de liberdade e de adrenalina. E sem falar que meus colegas me auxiliam o tempo todo, é um prazer ter um cara que já saltou dez mil vezes, te orientando e sentindo a mesma coisa que você está sentindo; nesta hora eu me sinto igual mesmo com 90 saltos. Assim passo a entender o porquê dos pássaros cantarem. Sinto-me como se o salto fosse o meu último. E que na hora que temos que sair do avião, dá um medo e vontade de desistir. E todos passam pelas mesmas experiências. O filme de minha vida passa em um segundo, e aí é que eu percebo como é bom viver".

A justificativa é o fato do grande risco envolvido na prática esportiva. Todos relataram a sensação de extrema adrenalina no corpo e os aspectos subjetivos, como o medo a ansiedade. Um pára-quedista sabe o que o outro vai passar e já passou durante a prática do esporte e a solidariedade é muito presente. Pudemos observar que o mais experiente sempre auxilia o mais inexperiente com um alto grau de solidariedade entre eles. Um dos membros do grupo sentiu isso quando realizava o curso e os saltos. Aqui se percebe o que Dejours (1992) afirma: que executar uma tarefa sem envolvimento material ou afetivo exige esforço de vontade que em outras circunstâncias é suportado pelo jogo da motivação e do desejo. Nesta vemos alguns aspectos, pelo fato de ocorrer algum problema no ar o pára-quedista ter que se virar com os materiais que ele possui no momento, e se ele desmotivar-se poderá morrer. $\mathrm{O}$ jogo afetivo envolvido pelo outro que salta, junto à solidariedade, 
contribui para que o sujeito tenha o desejo de voltar a experimentar novamente o prazer de saltar.

Entre os seis entrevistados, quatro fizeram referências a seus ambientes de trabalho, sendo insatisfatórios no início; antes da prática do pára-quedismo, eles achavam o trabalho estressante.

O.A.P., 29 anos, solteiro, gerente de RH, salta de pára-quedas há dois anos e três meses: "O meu ambiente de trabalho é uma masmorra, eu me sinto como se estivesse preso e sendo torturado. Eu não posso falar o que penso e o que sinto. $\mathrm{O}$ meu ambiente de trabalho me impede de demonstrar sentimentos, tenho que ser sempre impessoal, é a exigência da empresa onde trabalho, de não demonstrar sentimentos. Para mim, o chefe é o grande algoz, e qualquer passo em falso que eu der, "posso_colocar tudo a perder" e serei responsabilizado pelo ato. No entanto, após um salto aqui no aeroclube, sinto-me prazeroso e volto ao trabalho amanhã com a maior satisfação, e as exigências para mim serão mais uma forma de sentir prazer. $\mathrm{O}$ que antes representava para mim um verdadeiro calvário".

L.P.A., 55 anos, casado, técnico contábil há 30 anos, salta de pára-quedas há 14 anos. "O meu ambiente de trabalho representava uma tortura, e quando lembrava que ao acordar teria que ir à empresa sentia-me como se estivesse indo ao matadouro. Odiava o local. E este desânimo estava colocando-me em situações constrangedoras na qual o errar "pode colocar tudo a perder!"

M.J.O., 46 Anos, divorciado, torneiro mecânico, saltador de pára-quedas há 7 anos. "Meu ambiente de trabalho é um tormento e as minhas ações lá devem ser precisamente calculadas e eu tenho a obrigação de não poder errar. Qualquer erro cometido "poderei colocar tudo a perder!" E terei que iniciar tudo de novo e com mais trabalho, pelo fato de ficar cansado e de ter perdido tempo com a peça anterior".

H.J.L., 44 anos, casado, gerente administrativo há 5 anos e salta de pára-quedas há 2 anos. "Na empresa na qual trabalho não há a execução de práticas motivacionais de trabalho. Lá os relatórios têm uma exigência fora do normal. Estas exigências que me fazem, as refaço com os outros. $\mathrm{Na}$ empresa é "um acocha aqui e aperta ali, que todos ficam a ponto de explodir!"Aqui no Aero Clube eu retomei a disciplina que havia perdido há muito tempo. Sem falar que, se eu vacilar, poderei morrer a qualquer momento, então minha atenção, minha disciplina agora me faz viver e eu levo-as para o meu trabalho em que, na minha condição de gerente, seu descuidar ou vacilar, a empresa pode ter prejuízos incalculáveis. Lido com números e um descuido "poderei colocar tudo a perder", e levo a minha disciplina e atenção para minha casa e transmito para meus dois filhos".

Segundo a teoria dejouriana, como atrás se disse, o adoecimento pode acontecer devido a uma "retenção da energia pulsional" por uma situação de 
trabalho que impede a descarga adequada da carga psíquica. Dejours (1992) elaborou este conceito de "ideologia defensiva, que nesta posição em que o sujeito está inserido, caso não tenha outras formas de liberar toda sua energia psíquica, pode adoecer como forma do corpo de defender-se. E o pára-quedismo vem como construção social que possibilita dominar e tentar fazer desaparecer da consciência o sofrimento". Mas também este fragmento: "Posso colocar tudo a perder", pode ser encarado como uma reprodução do ambiente de trabalho que o trabalhador levou para aplicar na prática do pára-quedismo. Pela forma em que a atenção no momento do salto, deverá estar totalmente voltada para o mínimo cuidado necessário para que o salto seja perfeito. E aí a perfeição volta ao ambiente de trabalho, mas com outra configuração, agora de maneira que gere prazer.

$\mathrm{O}$ treinamento do pára-quedismo exige uma boa filtragem dos estímulos estressantes de modo que, independente da situação envolvida, o esportista deva estar sempre preparado, requerendo bastante disciplina e atenção. Qualquer descuido pode ser fatal. Dois dos trabalhadores usaram o pára-quedismo como analogia à prática organizacional, "um descuido pode botar tudo a perder" sic. E retomando a teoria de Dejours (1994), este refere que o sofrimento, por seu turno, é desdobrado: o ponto de incidência proveniente das ações mecânicas, conteúdo ergonômico da tarefa, é o corpo e não o aparelho mental; esse último será afetado pela insatisfação propiciada pelo conteúdo significativo da tarefa a ser executada, transformando em sofrimento bem particular, cujo alvo, antes de tudo, é a subjetividade, ou seja, a mente.

Jacques (1996) reforça que, com a implantação do modo de produção capitalista, passou-se a ver o homem apenas como agente produtivo, e não mais como ser dotado de sentimentos, desejos e necessidades próprias. Isto está causando uma profunda e radical transformação social e no modo de viver do homem. Continuando, abaixo veremos o discurso dos seis funcionários, em que uns tinham cargos de chefia e reportavam dizendo que precisavam liderar e agir em momentos de stress com a mente tranqüila.

O pára-quedismo tinha dado a eles essa capacidade, de se sentirem mais tranqüilos em ambientes estressores, e de lidar melhor com estímulos que poderiam irritá-los, de modo que viesse a atrapalhar o trabalho desses profissionais; pois a empresa continua querendo um bom desempenho na realização do trabalho, embora não ofereça meios que possibilitem uma boa recuperação ou capacitação. Eles alegaram que, com a prática do pára-quedismo, liberam o stress do trabalho, se sentem renovados, como se tivessem nascido novamente.

H.J.L, 44 anos, casado, gerente administrativo há cinco anos e salta de pára-quedas há dois anos: "Eu era muito agressivo e intolerante comigo e com os outros. Eu vivia procurando algo para controlar a minha insatisfação, eu nunca ficava satisfeito com nada. Tinha que decidir, e os que trabalhavam 
comigo esperavam isto de mim, sem falar que o meu trabalho é muito agitado. Ao praticar este esporte comecei a melhorar na empresa e as coisas para mim passaram a fazer sentido".

L.P.A., 55 anos, casado, técnico contábil há trinta anos, salta de pára-quedas há catorze anos: "Hoje trabalho com a mesma sensação que tive no primeiro dia de trabalho. Todos no escritório da empresa me dizem que sou outro homem, reaprendi a gostar do que faço. E faço bem feito! Com a prática eu tive um bom preparo físico, e melhorou meu desempenho com os outros; eu sentia muitas dores nos ombros, o que fazia com que eu passasse o tempo todo reclamando. Mudei e passei a reclamar menos, que até os meus patrões voltaram a me elogiar".

M.J.O., 46 Anos, divorciado, torneiro mecânico, saltador de pára-quedas há sete anos. "O meu local de trabalho não me ajuda, ele é quente, sujo, e os poucos moveis existentes são ruins, deixava-me pior. Às vezes sentia que estava no inferno. Passei a sentir-me melhor, hoje não sinto mais dificuldades em respirar, a prática deixou-me com uma resistência física melhor. Com o pára-quedismo eu passei a ver o mundo de outra forma".

O.A.P., 29 anos, solteiro, gerente de RH, salta de pára-quedas há dois anos e três meses: "Agora eu me sinto bem, fazendo o que faço, porque eu estou produzindo mais e melhor. Como passo a maior parte do tempo no escritório, eu tenho feito outras atividades esportivas, como capoeira, e isso tem me deixado mais satisfeito, motivado e com um corpo que eu acho sexy".

J.J.S., 35 anos, casado, advogado há seis anos e praticante de pára-quedismo há dois anos: "Sinto o prazer em ganhar uma causa, coisa que havia perdido; agora tenho mais um motivo de lazer que me deixa como se estivesse em uma grande partida de futebol, na qual tenho que fazer golo. Minha vida na empresa agora é outra, me sinto diferente, sou feliz onde trabalho e gosto da profissão que escolhi. Além disso, com a prática, tenho feito academia para ter um bom condicionamento físico e isto tem impressionado a mim e a minha família".

A.T.A.F., 55 anos, viúvo, arquiteto há trinta anos, há quatro que prática pára-quedismo: "O meu local de trabalho hoje é um ambiente que me proporciona prazer, antes eu me sentia como se estivesse em uma gaiola, preso e com desejo de fugir, sem rumo. Eu me sinto com um corpo melhor, tenho que me preparar para realizar uma boa aterrissagem, o que me deixa com mais ânimo com o trabalho. Cara, eu estou mais descontraído e meus amigos gostam de sair comigo e sentem-se bem ao meu lado. Eu tenho feito exercício para realizar bons saltos e isso me ajuda a manter a forma, e o meu condicionamento físico me proporciona uma aparência melhor".

Fazendo uma ponte dos discursos dos sujeitos com a teoria de Dejours observamos que, sob essa ótica, as conseqüências de situações relacionadas ao trabalho causam um enfraquecimento das estratégias coletivas, do 
ambiente, das condições de trabalho. Tais situações abordadas acima são vistas como causas de sofrimento para os trabalhadores.

De entre os seis sujeitos entrevistados, todos dizem se sentir bem com a prática do esporte no sentido de melhorar suas condições de trabalho; eles relacionaram a prática esportiva com um melhor condicionamento físico, um melhor preparo e relaxamento mental alcançado após o salto, servindo de ferramentas efetivas para a realização de suas atividades no trabalho. Observou-se que os trabalhadores mudaram sua situação de trabalho pela prática do pára-quedismo.

É unânime a opinião dos seis entrevistados quanto à questão do stress, sempre aparecendo em duas categorias: momento do salto e momento da aterrissagem. Inicialmente pode parecer como um sofrimento associado à prática deste esporte. Na verdade, acaba sendo justamente o contrário. Após a carga enorme de adrenalina liberada no organismo durante a prática do esporte na aterrissagem, há um relaxamento e um anestesiamento, como uma sensação de dormência no corpo. Os seis entrevistados relataram como sendo uma sensação de prazer e conforto, ao mesmo tempo que, no momento do salto, eles se esquecem do passado e não pensam no futuro. Visto a profundidade da experiência do salto, todos os sentidos estão aguçados e alerta para que nada possa ocorrer de forma incoerente face aos procedimentos de segurança. Vemos isto bem forte no discurso de: O.A.P., 29 anos: "O stress que eu sinto, eu descarrego tudo no salto, mesmo sabendo que eu estava antes pensando como é complicado deparar com a morte e com a liberdade. $O$ meu coração parece que vai sair da caixa torácica, mas senti-me leve como se estivesse tomando uma dose de anestesia, meu corpo está em estado de êxtase. Quando estou lá em cima, esqueço-me de tudo e vivo este momento único como se fosse o último".

De entre os seis entrevistados, um relatara sentir prazer ao conversar com outras pessoas no ambiente de trabalho sobre a prática deste esporte. Sendo momentos marcados por um sentimento de realização e diferença dos demais, onde a maioria das pessoas comenta ser necessário ter coragem para a prática deste esporte.

A.T.A.F., 55 anos, viúvo, arquiteto há trinta anos e há quatro pratica pára-quedismo: "Eu me sinto um super-homem porque pratico este esporte. As pessoas alegam que para saltar de pára-quedas é necessário coragem e disposição para correr risco de vida".

O orgulho que o praticante sente de dizer em praticar este esporte também foi comentado por um dos entrevistados, de forma a nos fazer observar que certo "respeito" e "admiração" é nutrida pelas pessoas do meio social destes praticantes. Eles relataram o pedido dos amigos do trabalho para ver seus vídeos dos saltos de forma contínua e a forma como os outros profissionais os observavam também foi relatada como algo muito produtivo. 
H.J.L, 44 anos, casado, gerente administrativo há cinco anos e salta de pára-quedas há dois anos:" Eu me sinto orgulhoso de ser saltador de pára-quedismo. Eu sei que não é esporte para qualquer pessoa".

Um dos entrevistados relata a importância da família em se preocupar pela segurança do trabalhador para que ele consiga enfrentar as situações de adversidade. Assim, a forma como eles vêem a insegurança é como algo complicado na vida de qualquer pessoa. Visto isto como o reconhecimento da prática esportiva como atividade segura e motivadora da mudança de vida do trabalhador.

J.J.S., 35 anos, casado, advogado há seis anos e praticante de pára-quedismo há dois anos: "Minha mãe e meu pai dissram que eu não estava bem das idéias quando decidi saltar de pára-quedas, minha esposa até ameaçou de me deixar caso eu continuasse com a prática. Ao saltar pela primeira vez e mostrar que é seguro, reconheceram como atividade segura".

Um dos entrevistados relatou ter um bom reconhecimento social por amigos e colegas. Disse sentir-se orgulhoso e disposto à prática do desafio. E Sampaio (2004) descreve que as patologias são desencadeadas pela busca incansável pelo reconhecimento. E Macêdo (2003) diz que, sendo assim, o trabalho pode significar realização de uma obra, através da qual o sujeito se expressa e é reconhecido pelos demais atores da sociedade, permanecendo para além da sua própria vida. E o trabalhador praticante de pára-quedismo consegue este reconhecimento por ser um esporte radical, que exige atenção, concentração e risco de vida.

J.J.S., 35 anos, casado, advogado há seis anos e praticante de pára-quedismo há dois anos: "Quando eu falo que faço pára-quedismo todos ficam abismados e começam a elogiar e dizem a mim que tem interesse de fazer o esporte e sentem-se dispostos a viver a emoção de ser pára-quedista".

Um dos entrevistados relatou sentir profundo medo e receio no início da prática do esporte, porém ressaltou que o desafio de se superar tinha sido o motivo pelo qual ele escolhia e mantinha a decisão de não desistir.

J.J.S., 35 anos, casado, advogado há seis anos e praticante de pára-quedismo há dois anos: "Eu gosto de fazer pára-quedismo, mas no meu primeiro salto "morri de medo". Com a continuidade, consegui superar este medo da morte. Sei que minha vida está sobre a proteção do velame e se ele falhar o resultado, você já imagina. Mesmo assim, prefiro fazer este esporte a outro, porque nele encontrei razões para eliminar a tensão dos dias trabalho e descobrir como vão meus limites emocionais, e por isso não desisto por nada.".

Com isso pegaremos no que fala Baptista (2001) para teorizar sobre a sensação de medo do trabalhador. O teórico considera o medo como algo genético, mas que está aberto às influências do ambiente, e que, por intermédio de sensibilização e habituação, pode diminuir ou aumentar. Pensando no 
contexto esportivo, o medo é uma desorganização psíquica que pode estar presente em quase todas as outras desarmonizações (ansiedade, apatia, alta intensidade emocional, etc.) antes, durante e após a competição. Assim Machado (2007) afirma que tal sensação chega a ser considerada uma das emoções mais negativas que o atleta pode experimentar, podendo, em alguns casos, destruir a harmonia psíquica do mesmo.

$\mathrm{O}$ medo do fracasso é tido, na literatura, como um dos temores mais gerais. Podendo ter distintas causas, como falta de confiança nas próprias capacidades e habilidades, ou medo da repercussão do fracasso, como castigos, afastamento, punições, entre outras. $\mathrm{O}$ medo de ser avaliado negativamente é justificado por Santiago e González (2006) pelo temor às críticas negativas que os indivíduos podem vir a receber, seja do professor, dos pais ou dos companheiros. $\mathrm{O}$ medo de fazer ridículo também é considerado da mesma maneira, pelo temor de ser avaliado e julgado pelos outros. Reforçando o que fala o trabalhador.

Dos seis, cinco relataram que era um sonho de criança saltar de pára-quedas e apenas um sugeriu que a prática do esporte veio de uma curiosidade sobre o que sentira saltando de avião.

J.J.S., 35 anos, casado, advogado há seis anos e praticante de pára-quedismo há dois anos: "Ao ver um avião, eu imaginava saltar um dia de lá de cima, era uma fantasia que não saía de minha mente, sempre sonhei em fazer pára-quedismo".

H.J.L, 44 anos, casado, gerente administrativo há cinco anos e salta de pára-quedas há dois anos: "Quando eu via filmes de guerra onde os soldados saltavam de pára-quedas eu ficavam imaginando como seria saltar. Com isso esta prática é um sonho de infância que está sendo concretizado".

A.T.A.F., 55 anos, viúvo, arquiteto há 30 anos e há quatro pratica pára-quedismo: "Sempre tive desejo de saltar de pára-quedas, é um sonho que graças a Deus tornei realidade".

O.A.P., 29 anos, solteiro, gerente de RH, salta de pára-quedas há dois anos e três meses: "Saltar de pára-quedas é um sonho realizado".

M.J.O., 46 Anos, divorciado, torneiro mecânico, saltador de pára-quedas há sete anos. "Eu me sinto sonhando quando salto de pára-quedas, sempre tive muita vontade de me ver pendurando no velame, é um sonho de infância realizado".

Piucco (2005) refere que os sujeitos envolvidos nas vivências junto à natureza têm efetivas oportunidades de auto-desafio e de rompimento com a monotonia do dia-a-dia, pois o risco é controlado pelo auxílio de dispositivos utilizados nas práticas de atividade física de aventura, proporcionando sensações, emoções e percepções bastante diversas daquelas do cotidiano, associadas aos sabores da aventura, do ineditismo, da novidade, que são características nessas práticas de lazer. 
O contato com a natureza faz o trabalhador esquecer-se do sofrimento e lembrar-se dos momentos bons da vida. Codo (1996) apud Veiga \& Silva (2007) afirma que "o trabalho é uma relação de dupla transformação entre o homem e a natureza, geradora de significado". (p. 25). Para Jacques (1996) apud Silva \& Veiga (2007), essa valorização e exaltação do trabalho na sociedade ocidental dão a ele um papel de destaque na constituição da identidade da pessoa, como vemos no discurso de J.J.S., 35 anos: "O pára-quedismo me faz entrar em contato com a natureza e este contato me faz esquecer dos meus problemas, a natureza me faz ser criança. Daí meu trabalho passou a ter mais significado. Quando eu entro em contato com a natureza, eu faço o meu trabalho, passa a ser mais simples”.

\section{Considerações Finais}

Após as análises e discussões feitas anteriormente, os resultados permitem fazer algumas considerações finais sobre a relação trabalho-homem como fonte estressora, pelas exigências do capitalismo e pela busca incessante de modificações de papéis sociais. A pesquisa realizada apresentou com maiores incidências uma estratégia dos trabalhares de enfrentar o stress, lidando com situações de limites, medos e fortes sensações de adrenalina, aliado com o "medo de não obter êxito", "medo de ser incompetente". E que a prática esportiva do pára-quedismo aumentou consideravelmente os níveis de autoconfiança dos sujeitos estudados, que se aproximam muito da expectativa de sucesso das ações com êxito na prática esportiva com o trabalho realizado no dia-a-dia.

Através da psicodinâmica dejouriana vimos como é possível evitar o sofrimento com atividades que aproximem o trabalhador da natureza, como demonstrado na literatura. E que isto é possível pelo discurso que é feito, onde o homem fala aquilo que sente. E através das teorias expostas podemos notar como o trabalho influencia na vida das pessoas, sendo visto como forma de segurança, identidade, como também sofrimento.

\section{Referências}

Albornoz, S. (2002). O que é trabalho (4. ${ }^{\mathrm{a}}$ ed.). São Paulo: Brasiliense.

Amatuzzi, M. M. (1990) Que é ouvir. Estudos de Psicologia, 7(2), ago./dez.

Azambuja, E. P. (2007). Significados do trabalho no processo de viver de trabalhadoras de um programa de saúde da família. Texto \& Contexto - enfermagem, Florianópolis, 16 (1).

Anderson, P. A. (1985). Crise do Marxismo. São Paulo: Brasiliense. 
Antonio, F. C. Qualidade de vida no trabalho, saúde e doença. São Paulo, Artigo.

Bakhtin, M. (1981). Marxismo e filosofia da linguagem. São Paulo: Hucitec.

Baptista, A. (2001). Perturbações do medo e da ansiedade: uma perspectiva evolutiva e desenvolvimental. In I. Soares (Org.), Psicopatologia do desenvolvimento: trajetórias (in) adaptativas ao longo da vida. Coimbra: Quarteto.

Brandão, M. R. F., Matsudo, V. K. R. (1990). Stress, emoção e exercício. Revista Brasileira de Ciência e Movimento. São Caetano do Sul.

Bruhns, H. T. (1997). Lazer e meio ambiente: Corpos buscando o verde e a aventura. Revista Brasileira de Ciências do Esporte. 18(2), 86-91.

Berger, P., Luckann, T. (1985). A construção social da realidade. Petrópolis: Vozes.

Codo, W. (2006). Um diagnóstico do trabalho - em busca do prazer. In W. Codo (Org.), Por uma psicologia do trabalho. Ensaios recolhidos. São Paulo: Casa do Psicólogo.

Codo, W., \& Jacques, M. G. (2002). Saúde mental e trabalho. Leituras. Petrópolis, RJ: Vozes.

Codo, W., Sampaio, J., \& Hitomi, A. (1998). Indivíduo, trabalho e sofrimento. Petrópolis, RJ: Vozes.

Cury, V. E. (1987). Psicoterapia centrada na pessoa: Evolução das formulações sobre a relação terapeuta-cliente. Dissertação de Mestrado não-publicada, Universidade de São Paulo, SP.

Drumond, V. A. T. (2002). O princípio da integração do trabalhador na empresa no sistema jurídico-constitucional brasileiro. Dissertação de Mestrado em Direito do Trabalho. Faculdade Mineira de Direito, Minas Gerais.

Dejours, C., Abdoucheli, E., \& Jayet, C. (1994). Psicodinâmica do trabalho. Contribuições da escola dejouriana à análise da relação prazer, sofrimento e trabalho. São Paulo: Atlas.

Dejours, C., (1992). A loucura do trabalho, Estudo de psicopatologia do trabalho. São Paulo: Cortez/Oboré.

Fernandes, R. C. (1998). Esportes Radicais: Referências para um estudo acadêmico. Conexões educação, esporte, lazer. São Paulo: Revista Brasileira de Ciência e Movimento, v. 2.

Freud, S. (1980). Um estudo autobiográfico. Inibições, sintomas e ansiedade. A questão da análise leiga e outros trabalhos. In Edição Standard das Obras Psicológicas completas (Vol. 20). RJ: Imago.

Fuganti, L. A. (1999). Saúde, desejo e pensamento. In A. Lancetti (Dir.), Saúde e loucura 2. São Paulo: Sucitec.

Gaspari, J. C., Schwarts, G. M. (2002). Inteligências múltiplas e representações. Psicologia: Teoria e Pesquisa, 18(3).

Gomes, C. L. (Org.) (2004). Dicionário crítico do lazer. Belo Horizonte: Autêntica.

Goffman, E. (1985). A representação do eu na vida cotidiana. 4. a ed. Petrópolis: Vozes.

Heloani, J. R. (1994). Organização do trabalho e administração: Uma visão multidisciplinar. São Paulo: Cortez. 
Jacques, M. G. (1996). Identidade e trabalho: Uma articulação indispensável. In A. Tamayo, J. E. Borges-Andrade \& W. Codo (Org.), Trabalho organizações e cultura. São Paulo: Coletâneas da ANPEPP.

Lindgren, H. C., \& Byrne, D. (1992). Psicologia: Personalidade e Comportamento Social. RJ: Sindicato Nacional dos Editores de Livros.

Lipovestsky, G. (2007). A felicidade Paradoxal. Ensaio sobre a sociedade do hiperconsumo. São Paulo: Companhia das Letras.

Lipovetsky, G. (2005). O império do efémero: A moda e seus destinos nas sociendades modernas. São Paulo: Companhia das Letras.

Luria, A. R. (1986). Pensamento e Linguagem: As últimas conferências de Luria. Porto Alegre: Artes Médicas.

Macêdo, S. M. (2006). As condições de trabalho e saúde mental entre profissionais de psicologia na região metropolitana do Recife: Um estudo fenomenológico. Travessia, VIII (1).

Machado, A. A. (orgs.) (2007). Coleção psicologia do esporte e do exercício: Teoria e aplicação. São Paulo: Atheneu.

Marcellino, N. C. (1996). Estudos do Lazer: Uma Introdução. São Paulo: Autores Associados.

Marx, K. (1996). Para a crítica da economia política do capital. São Paulo: Nova Cultural.

Moraes, L. C. A. (1990). Ansiedade e desempenho no esporte. Revista Brasileira de Ciência e Movimento. São Caetano do Sul.

Mucchielli, A. (1991). Les Méthodes Qualitatives. Paris: P.U.F.

Orlickas, E. (1997). Consultoria interna de recursos humanos. São Paulo: Makron Books.

Pagés, M. (1993). O poder das organizações: A dominação das multinacionais sobre os indivíduos. São Paulo: Atlas.

Pedinielli, J. L. (1999). Introdução à psicologia clínica. Lisboa: Climepsi.

Pino, A. (1995). Semiótica e cognição na perspectiva histórico-cultural. Temas em Psicologia, $n$. 2. São Paulo.

Piucco, T. (2005). Revista Digital - Buenos Aires - Año $10-N^{\circ} 89$ - Octubre de http://www.efdeportes.com.

Rouant, P. S. (1983) Teoria crítica e psicanálise. Rio de Janeiro: Tempo Brasileiro; Fortaleza: Edições Universidade Federal do Ceará.

Sampaio, J. R. (Org.) (2004). Qualidade de vida no trabalho e psicologia social. São Paulo: Casa do Psicólogo.

Sanches, C. (1999). Nova função para o profissional de RH. RH em Síntese. São Paulo: Gestão e RH Editora, Março/Abril.

Silva, N. I. A., \& Veiga, H. M. S. Construção de escala para avaliar sofrimento psíquico-social de trabalhadores desempregados. Revista Avaliação Psicológica, v.6.

Schultz, D. P., \& Schultz, S. E. (1992). História da psicologia moderna. $6^{a}$ ed. São Paulo: Cultriz.

Sousa Filho, D. M. (1983). Filosofia, linguagem e comunicação. São Paulo: Cortez. 
Statt, D. A. (1978). Introdução à Psicologia. SP: Ed. Harbra.

Tahara, A. K., \& Schwartz, G. M. (2002). Atividades de aventura: Análise da produção acadêmica do Enarel: Licere.

Tavares, C. (2007). Iniciação à visão holística. Rio de Janeiro: Record.

Watzlawick, P. (1967). Pragmática da Comunicação Humana: Um estudo dos padrões, patologias e paradoxos da interação. São Paulo: Cultrix. 